\title{
Effect of intensive glucose lowering treatment on all cause mortality, cardiovascular death, and microvascular events in type 2 diabetes: meta-analysis of randomised controlled trials
}

\author{
Rémy Boussageon general practitioner and lecturer ${ }^{1}$, Theodora Bejan-Angoulvant cardiologist, \\ pharmacologist, and lecturer ${ }^{234}$, Mitra Saadatian-Elahi epidemiologist ${ }^{2}$, Sandrine Lafont resident \\ in family medicine ${ }^{1}$, Claire Bergeonneau resident in family medicine ${ }^{13}$, Behrouz Kassaï \\ pharmacologist and lecture ${ }^{2345}$, Sylvie Erpeldinger general practitioner and lecturer ${ }^{1}$, James M \\ Wright anaesthesiologist, pharmacologist, and professor of anaesthesiology and pharmacology ${ }^{6}$, \\ François Gueyffier head of department and clinical investigation centre, cardiologist, and \\ professor ${ }^{2345}$, Catherine Cornu endocrinologist, pharmacologist, and research physician in clinical \\ investigation centre 2345
}

${ }^{1}$ Department of General Medicine, Université Claude Bernard Lyon 1, Lyon, France; ${ }^{2}$ Department of Clinical Pharmacology, Hospices Civils de Lyon, Lyon, France; ${ }^{3}$ UMR 5558, CNRS, Villeurbanne, France; ${ }^{4}$ Université Claude Bernard Lyon 1, Lyon, France; ${ }^{5}$ Clinical Investigation Centre, Louis Pradel Hospital, Bron, France; ${ }^{6}$ Departments of Anaesthesiology, Pharmacology, and Therapeutics and Medicine, University of British Columbia, Vancouver, BC, Canada

\begin{abstract}
Objective To determine all cause mortality and deaths from cardiovascular events related to intensive glucose lowering treatment in people with type 2 diabetes.

Design Meta-analysis of randomised controlled trials.

Data sources Medline, Embase, and the Cochrane database of systematic reviews.

Study selection Randomised controlled trials that assessed the effect of intensive glucose lowering treatment on cardiovascular events and microvascular complications in adults ( $\geq 18$ years) with type 2 diabetes.

Data extraction Primary end points were all cause mortality and death from cardiovascular causes. Secondary end points were severe hypoglycaemia and macrovascular and microvascular events.

Synthesis of results Results are reported as risk ratios with 99\% confidence intervals. Statistical heterogeneity between trials was assessed with $\mathrm{X}^{2}, \mathrm{\tau}^{2}$, and $\mathrm{I}^{2}$ statistics. A fixed effect model was used to assess the effect on the outcomes of intensive glucose lowering versus standard treatment. The quality of clinical trials was assessed by the Jadad score.
\end{abstract} Results 13 studies were included. Of 34533 patients, 18315 received
intensive glucose lowering treatment and 16218 standard treatment.
Intensive treatment did not significantly affect all cause mortality (risk
ratio $1.04,99 \%$ confidence interval 0.91 to 1.19$)$ or cardiovascular death
(1.11, 0.86 to 1.43 ). Intensive therapy was, however, associated with
reductions in the risk of non-fatal myocardial infarction $(0.85,0.74$ to
$0.96, \mathrm{P}<0.001)$, and microalbuminuria ( $0.90,0.85$ to $0.96, \mathrm{P}<0.001)$ but
a more than twofold increase in the risk of severe hypoglycaemia $(2.33$,
21.62 to $3.36, \mathrm{P}<0.001)$. Over a treatment period of five years, 117 to
150 patients would need to be treated to avoid one myocardial infarction
and 32 to 142 patients to avoid one episode of microalbuminuria,
whereas one severe episode of hypoglycaemia would occur for every
15 to 52 patients. In analysis restricted to high quality studies (Jadad
score $>3)$, intensive treatment was not associated with any significant
risk of reductions but resulted in a $47 \%$ increase in risk of congestive
heart failure (P<0.001).
Conclusions The overall results of this meta-analysis show limited
benefits of intensive glucose lowering treatment on all cause mortality
and deaths from cardiovascular causes. We cannot exclude a $9 \%$
reduction or a $19 \%$ increase in all cause mortality and a $14 \%$ reduction or a $43 \%$ increase in cardiovascular death. The benefit:risk ratio of 
intensive glucose lowering treatment in the prevention of macrovascular and microvascular events remains uncertain. The harm associated with severe hypoglycaemia might counterbalance the potential benefit of intensive glucose lowering treatment. More double blind randomised controlled trials are needed to establish the best therapeutic approach in people with type 2 diabetes.

\section{Introduction}

Worldwide, the number of adults with diabetes was estimated at 150 million in 2000, a figure that is expected to increase to 366 million by $2030 .{ }^{1}$ Epidemiological evidence indicates that type 2 diabetes is an independent risk factor for cardiovascular disease and microvascular complications, such as retinopathy. The rate of cardiovascular disease is about twice as high in people with diabetes than without. ${ }^{23}$ Intensive glycaemic control has been suggested as an effective treatment to reduce the burden of cardiovascular disease and microvascular complications in people with diabetes. ${ }^{4}$ Current guidelines recommend a target glycated haemoglobin level $\left(\mathrm{HbA}_{1 \mathrm{c}}\right)$ of $7 \%$ or less. ${ }^{5}$ The results of major randomised clinical trials on the benefits of such treatment are, however, controversial. ${ }^{6-8}$ In the Action to Control Cardiovascular Risk in Diabetes (ACCORD) study an intensive glucose lowering regimen was associated with increased mortality (hazard ratio 1.22, 95\% confidence interval 1.01 to $1.46, \mathrm{P}=0.04) .{ }^{7}$ In three major recent trials the rates of hypoglycaemia and weight gain were significantly higher in the groups receiving intensive therapy. In none of these studies did intensive therapy decrease cardiovascular events. A statistically significant reduction in the rate of microvascular and renal events after intensive glycaemic control was reported in the United Kingdom Prospective Diabetes Study (UKPDS) 33 on intensive blood glucose control with sulfonylureas or insulin compared with conventional treatment and risk of complications in patients with type 2 diabetes $^{9}$ and the Action in Diabetes and Vascular disease: preterAx and diamicroN mr Controlled Evaluation (ADVANCE) ${ }^{6}$ trial, whereas in the Veterans Affairs Diabetes Trial $(\text { VADT })^{8}$ microvascular complications were the same in both the intensive therapy and the control groups.

Several meta-analyses evaluating the effect of intensive glucose lowering in people with diabetes are currently available. However, these published meta-analyse ${ }^{10-12}$ focused mainly on the effect of treatment on macrovascular events, such as myocardial infarction. We carried out an updated meta-analysis taking into consideration both microvascular complications and cardiovascular events as well as severe hypoglycaemia related to intensive glycaemic control and the level of evidence of the selected studies.

\section{Methods}

We searched for studies through Medline, Embase, and the Cochrane database of systematic reviews (January 1950 to July 2010) without any language restriction. Key words used were "type 2 diabetes", "diabetes mellitus", "cardiovascular diseases", "coronary disease", "stroke", "peripheral vascular diseases", "retinopathy", "neuropathy", "albuminuria", "renal failure", "congestive heart failure", "hypoglycaemic agents", "glucose control", "glycaemic control", and "tight glucose control". Furthermore, we reviewed the reference lists of published meta-analyses. Overall, 147 abstracts were reviewed.

\section{Study selection}

Two investigators (RB, SL) independently reviewed the identified abstracts or manuscripts to determine the eligibility of the studies for inclusion in the meta-analysis. Eligibility criteria were randomised controlled trials assessing the efficacy of intensive glucose lowering treatment (oral or insulin) versus a standard treatment (standard care), less intensive glycaemic lowering treatment, or placebo (intensive glycaemic treatment could be defined either by a specified $\mathrm{HbA}_{1 \mathrm{c}}$ target or by treatment intensification); trials using clinically relevant outcomes; and participants aged 18 or older with type 2 diabetes.

\section{Quality assessment}

Two independent investigators ( $\mathrm{RB}, \mathrm{CC})$ used the Jadad score to assess the quality of selected articles. ${ }^{13}$ Double blind randomised placebo controlled trials received a score of more than 3 , whereas open randomised trials were given a score of 3 or less.

\section{End points}

Primary end points were all cause mortality and death from cardiovascular causes. Secondary end points were myocardial infarction, non-fatal myocardial infarction, stroke (fatal and non-fatal), congestive heart failure, photocoagulation, retinopathy (new or worsening), visual deterioration or blindness, neuropathy (new or worsening), microalbuminuria (new or worsening), renal failure (occurrence of renal failure or doubling of serum creatinine level), peripheral vascular events (leg revascularisation, peripheral arterial disease, or intermittent claudication), amputation, and severe hypoglycaemia.

Definitions of both primary and secondary end points correspond to those reported in the originally published papers. These criteria were not available for all studies included in the meta-analysis. Evaluations were not always based on the overall study population.

Two reviewers (RB and $\mathrm{CC}$ ) independently and in duplicate extracted data for all the outcomes of interest from the included trials.

\section{Statistical analysis}

To standardise the reporting of our results we calculated risk ratios and $99 \%$ confidence intervals from the number of events or participants in each group for every trial. We used fixed effect model meta-analysis to assess the effect of intensive glucose lowering versus standard treatment on the outcomes of interest. The $\chi^{2}(\mathrm{P}<0.1)$ and $\mathrm{I}^{2}$ statistics were used to assess statistical heterogeneity across trials. The $\mathrm{I}^{2}$ statistic is derived from Cochran's Q-that is, $[(\mathrm{Q}-\mathrm{df} / \mathrm{Q}) \times 100]$ - and measures the proportion of overall variation that is attributable to between study heterogeneity. The statistical test of heterogeneity was significant if the $\mathrm{P}$ value was less than 0.1 , and heterogeneity was considered high if the $\mathrm{I}^{2}$ statistic was greater than $50 \%$. To determine the size and clinical relevance of heterogeneity when detected by means we calculated $\tau^{2}$. We used a random effect model when the statistical test of heterogeneity showed significance.

To illustrate the impact of treatment strategy, we derived the range of absolute risk reductions by computing the range of the risks for the end point considered in the control group of the three most powerful and recent trials (ACCORD, ADVANCE, and VADT) over a five year period. We then multiplied the extreme values of this range by the common risk reduction estimate. The number of patients needed to be treated to prevent (benefit) or provoke (harm) an event was the opposite of the absolute risk reduction.

Sensitivity analysis was carried out according to the Jadad score. When possible we carried out all statistical analyses according to the intention to treat principle. Because of multiple 
comparisons, all $\mathrm{P}$ values were two sided $(\mathrm{P}<0.01)$. Analyses were done using Revman software version 5 (www.cc-ims.net/ revman).

\section{Results}

Figure 1 shows the selection of studies. Eight trials were excluded: the Diabetes Control and Complications Trial $(\mathrm{DCCT})^{14}$ concerned people with type 1 diabetes; the Diabetes, Insulin Glucose Infusion in Acute Myocardial Infarction (DIGAMI) trial ${ }^{15}$ evaluated the effect of short term glycaemic control in people with acute myocardial infarction; A Diabetes Outcome Progression Trial (ADOPT) ${ }^{16}$ and Rosiglitazone Evaluated for Cardiac Outcomes and Regulation of Glycemia in Diabetes (RECORD $)^{17}$ did not assess intensive glucose lowering treatment or drug versus placebo; Diabetes REduction Assessment with ramipril and rosiglitazone Medication $(\text { DREAM })^{18}$ and Nateglinide And Valsartan in Impaired Glucose Tolerance Outcomes Research (NAVIGATOR) ${ }^{19}$ concerned patients with impaired glucose tolerance; STENO $2^{20}$ tested several interventions and therefore did not assess intensive glucose lowering treatment compared with standard treatment; and the UKPDS $44^{21}$ reported intermediate end points rather than clinical end points of interest for this meta-analysis.

Overall, 13 randomised controlled trials fulfilled the inclusion criteria and were included in the meta-analysis. $.^{6-9} 22-30$ The table summarises the baseline characteristics of the selected studies. Trials included five double blind controlled trials with a Jadad score of more than 3 (UGDP phenformin, ${ }^{22}$ UGDP tolbutamide, ${ }^{23}$ PROactive, ${ }^{28}$ Dargie et al, ${ }^{29}$ Hyperinsulinemia: the Outcome of its Metabolic Effects (HOME) ${ }^{30}$ ) and eight open trials with a Jadad score of 3 or less (UGDP insulin, ${ }^{24}$ the Kumamoto study, ${ }^{25}$ Veterans Affairs Feasibility Study 1997, ${ }^{26}{ }^{31}$ UKPDS 33, ${ }^{9}$ UKPDS $34,{ }^{27}$ ACCORD,${ }^{732}{ }^{33}$ ADVANCE, ${ }^{6}$ and VADT ${ }^{8}$ ). These studies' results on microangiopathy were published separately: VADT $^{31}$ and ACCORD. ${ }^{32} 33$

The UGDP studies, one on phenformin versus placebo ${ }^{22}$ the other on tolbutamide versus placebo ${ }^{23}$ were combined. As these drugs have been withdrawn, a sensitivity analysis was carried out with the combined trial excluded from the meta-analysis. A further UGDP study evaluated the effect of intensive versus standard insulin therapy in people with diabetes. ${ }^{24}$ The UKPDS $33^{9}$ and $34^{27}$ studies were combined. Contrary to an earlier meta-analysis, ${ }^{10}$ the control group $(n=411)$ was included only once in the present study. UGDP and UKPDS included patients with either diabetes or impaired glucose tolerance. However, the mean plasma glucose at inclusion $-143.2 \mathrm{mg} / 100 \mathrm{~mL}$ in UGDP and $8.0 \mathrm{mmol} / \mathrm{L}$ (range $7.1-9.7$ ) and $8.1 \mathrm{mmol} / \mathrm{L}$ (7.1-9.7), in UKPDS 33 and 34, respectively, are compatible with the diagnosis of diabetes. A sensitivity analysis without UGDP and UKPDS was done.

The analysis was based on 34533 patients (60\% men), with a mean age of 62 (range 49-66) years, a baseline mean $\mathrm{HbA}_{1}$ level of $7.9 \%$ (range 7.1-9.5\%), and a mean body mass index of 31 (range 20-32). The mean duration of diabetes was 7.8 (range 0-12) years. Overall, 39\% of patients already had a cardiovascular event at baseline. In total, 18315 were randomised to the intensive treatment group and 16218 to the standard treatment group. The mean duration of follow-up was 5.0 (range 1-10) years.

\section{Primary end points}

Intensive treatment did not significantly affect all cause mortality (risk ratio $1.04,99 \%$ confidence interval 0.91 to 1.19 ) or death from cardiovascular causes (1.11, 0.86 to 1.43 ; fig 2).
Heterogeneity between trials was significant for all cause mortality $\left(\mathrm{P}=0.09, \tau^{2}=0.01, \mathrm{I}^{2}=42 \%\right)$ and for cardiovascular deaths $\left(\mathrm{P}=0.006, \tau^{2}=0.04, \mathrm{I}^{2}=61 \%\right)$. After exclusion of trials with a Jadad score of 3 or less (see web extra), the estimated odds ratio for all cause mortality did not change (1.06, 0.84 to 1.34), whereas the rate of cardiovascular deaths tended to be higher, although not significantly, in the intensive treatment group $(1.58,0.60$ to 4.17$)$. Heterogeneity among high quality trials was persistent for the rate of cardiovascular deaths $\left(I^{2}=70 \%\right)$. This heterogeneity could not be explained.

\section{Secondary end points}

Figure 3 summarises the effect of intensive treatment versus standard treatment on macrovascular complications. In the intensive treatment group the rate of non-fatal myocardial infarctions was significantly reduced $(0.85,0.74$ to 0.96 ; $\mathrm{P}<0.001)$ and there was a non-significant trend towards a reduction of all myocardial infarctions $(0.90,0.81$ to 1.01 ; $\mathrm{P}=0.02)$. No heterogeneity existed between trials for these end points $\left(I^{2}=0 \%\right)$. However, no trial showed a significant risk reduction by itself on these two criteria. When trials of high quality (see web extra) were only considered, the observed benefit for non-fatal myocardial infarctions $(0.83,0.63$ to 1.10$)$ disappeared and the rate of all myocardial infarctions tended to be higher, although not significantly, in the intensive treatment group $(1.34,0.77$ to 2.35$)$. Data on all myocardial infarctions were not available for the PROactive study.$^{28}$ For all myocardial infarctions, the five year absolute risk reduction ranged from $0.7 \%$ to $0.9 \%$. The number of patients needed to be treated to prevent one event was 150 to 117.

Intensive treatment was not associated with a reduction in the risk of non-fatal strokes (1.00, 0.83 to 1.21 ; fig 3$)$, all strokes $(0.96,0.83$ to 1.13 ; fig 3$)$, or congestive heart failure $(1.17,0.91$ to 1.50 ; fig 4). Heterogeneity was evident among studies for congestive heart failure $\left(\mathrm{P}=0.01, \tau^{2}=0.04, \mathrm{I}^{2}=59 \%\right)$, but not for the two other end points. The analysis restricted to high quality trials (see web extra) could be carried out only for all strokes $(0.81,0.57$ to 1.17$)$ and for congestive heart failure $(1.47,1.19$ to 1.83$)$.

Figures 5-7 summarise the effect of intensive treatment versus standard treatment on microvascular complications. Intensive treatment was associated with a significant reduction in only one end point - the rate of microalbuminuria $(0.90,0.85$ to 0.96 ; fig 6). This result relies mainly on three larger trials: ACCORD, ${ }^{7}$ ADVANCE, ${ }^{6}$ and UKPDS. ${ }^{27}$ Absolute risk reductions for microalbuminuria ranged from $0.7 \%$ to $3.1 \%$. The corresponding numbers for patients needed to be treated were 142 to 32 . The rate of peripheral vascular events did not differ between the two groups $(0.98,0.84$ to 1.13 ; fig 6$)$. Heterogeneity between trials for this end point was not significant $\left(\mathrm{P}=0.16, \mathrm{I}^{2}=34 \%\right)$. When the analysis was limited to high quality studies (see web extra), the risk of peripheral vascular events remained non-significant $(1.34,0.95$ to 1.90$)$.

The intensive treatment and standard treatment groups did not differ in the rate of retinopathy $(0.85,0.71$ to 1.03 ; fig 5$)$, photocoagulation $(0.91,0.71$ to 1.17 ; fig 5$)$, visual deterioration or blindness $(1.00,0.96$ to 1.05 ; fig 6$)$, neuropathy $(0.99,0.95$ to 1.03 ; fig 6 ), renal failure or doubling of serum creatinine levels (1.03, 0.98 to 1.08 ; fig 6 ), and fatal or non-fatal amputation (0.84, 0.54 to 1.29 ; fig 7$)$. Between trial heterogeneity was observed for retinopathy $\left(\mathrm{P}=0.03, \tau^{2}=0.02\right.$, $\left.\mathrm{I}^{2}=54 \%\right)$ and for photocoagulation $\left(\mathrm{P}=0.07, \tau^{2}=0.02, \mathrm{I}^{2}=57 \%\right)$. After exclusion of trials with a Jadad score of less than 3 (see web extra), heterogeneity disappeared and the effect of intensive 
treatment was no longer significant for microalbuminuria $(0.99$, 0.87 to 1.13 ). The exclusion of the UGDP trial (phenformin and tolbutamide trials combined) did not change the results.

\section{Severe hypoglycaemia}

Compared with the standard treatment group, the risk of severe hypoglycaemia was more than twice as high in the intensive treatment group $(2.33,1.62$ to 3.36 ; fig 8$)$. Heterogeneity was evident among studies $\left(\mathrm{P}=0.03, \tau^{2}=0.05, \mathrm{I}^{2}=63 \%\right)$. Absolute five year risk increases in severe hypoglycaemia ranged from $1.9 \%$ to $6.6 \%$, making the number of patients needed to harm between 52 and 15.

\section{Discussion}

This meta-analysis of data from 13 randomised controlled trials showed no benefit of intensive glucose lowering treatment on all cause mortality or death from cardiovascular causes in adults with type 2 diabetes. Furthermore, a 19\% increase in all cause mortality and a $43 \%$ increase in death from cardiovascular causes cannot be ruled out. Other meta-analyses have shown a significant $15 \%$ relative reduction in the rate of non-fatal myocardial infarctions. ${ }^{10-12}$ Only one study $\left(\right.$ ACCORD $\left.^{7}\right)$ found a protective effect of intensive treatment on myocardial infarction, counterbalanced by an increase in overall mortality. A reduction in myocardial infarctions without a reduction in mortality must be considered cautiously. Since it is estimated that $50 \%$ of patients with myocardial infarctions die before receiving medical attention, a reduction of myocardial infarctions should have some impact on the mortality. Intensive glucose lowering treatment was associated with a significant $10 \%$ reduction in the risk of microalbuminuria, without significant benefit on other important clinical microvascular complications such as neuropathy, retinopathy, visual deterioration, or renal failure. The favourable results on non-fatal myocardial infarction and microalbuminuria did not remain significant when the analysis was restricted to studies of high quality (Jadad score $>3$ ), whereas a $47 \%$ increase in the risk of congestive heart failure became significant. As reported by others, intensive treatment was associated with a significant twofold increased risk of severe hypoglycaemia.

\section{Strengths and limitations of the study}

Our meta-analysis is more powerful (seven trials and 34533 patients) than previously published meta-analyses in the Annals of Internal Medicine (five trials and 27802 patients) and Lancet (five trials and 33040 patients). Previous meta-analyses focused on cardiovascular events but not on microvascular events (retinopathy, nephropathy) or peripheral arterial disease. Finally, we present the results using numbers needed to treat and numbers needed to harm, which allows benefits and harms to be balanced in a more explicit way.

Another strength of this meta-analysis was to carry out a sensitivity analysis based on the level of evidence.

Randomisation and concealment of allocation are of central importance in clinical trials to prevent selection bias, but they do not prevent biases related to the evaluation, the follow-up, or the "placebo effect." This is why double blinding is required to reduce bias when evaluating a specific treatment effect. We explored the impact of blinding by testing whether the treatment effect was sensitive to the removal of trials that were not blinded. This analysis did not change our conclusions.

This study has some limitations. As in other meta-analyses, publication bias may occur. The treatment strategies applied and the targeted glycaemic level (if any) varied across trials, as did the definitions of outcomes, trial designs, and duration of follow-up. This is likely to explain at least some of the observed heterogeneity.

\section{Policy implications}

Overall, the absolute benefit of treatment for five years was modest; 117 to 150 people would need to be treated to avoid one myocardial infarction, 32 to 142 to avoid one episode of microalbuminuria, and 15 to 52 to avoid one severe hypoglycaemic event. The occurrence of severe hypoglycaemia has been strongly related to the incidence of major macrovascular events in a retrospective analysis of the ADVANCE study ${ }^{6}$ (hazard ratio $2.88,95 \%$ confidence interval 2.01 to 4.12$)$, major microvascular events $(1.81,1.19$ to 2.74$)$, death from cardiovascular causes $(2.68,1.72$ to 4.19$)$, and all cause mortality $(2.69,1.97$ to 3.67$){ }^{34}$

Our analyses emphasise the lack of high quality trials to investigate the impact of intensive glucose lowering treatment on the occurrence of macrovascular and microvascular events in people with type 2 diabetes. We also emphasise the overall low level of evidence on the efficacy of glucose lowering treatment compared with other kinds of preventive measures against cardiovascular events.

The absence of benefits from intensive glucose lowering treatment further illustrates why relying on surrogate end points for treating people is a fallacy. Marketing new drugs based only on evidence that they decrease glucose or $\mathrm{HbA}_{1 \mathrm{c}}$ plasma levels, or both, should not be allowed. Practitioners (and patients) should not rely on either blood glucose targets or $\mathrm{HbA}_{1 \mathrm{c}}$ targets or the concept of "the lower the better." A recent retrospective cohort study reported a significant increase in all cause mortality in people in the lowest 10ths for $\mathrm{HbA}_{1 \mathrm{c}}$ level $(6.4 \%$, hazard ratio $1.52,95 \%$ confidence interval 1.32 to 1.76 ) and highest 10ths $(10.5 \%, 1.79,1.56$ to 2.06$) .^{35}$

It is paradoxical to propose intensive glucose lowering treatment when available drugs have no proved intrinsic efficacy. Most clinical trials evaluating the efficacy of drugs to lower glucose levels in people with diabetes used HbA1c levels as the primary outcome, ${ }^{36}$ and this is considered sufficient for licensing. In addition, few double blind placebo controlled trials have evaluated treatments for diabetes based on clinically relevant criteria. $^{22} 2328-30$

\section{Comparison of results with individual drug trials}

From available data, metformin is the most effective oral treatment for glycaemic control in overweight people with diabetes, ${ }^{38}{ }^{39}$ despite numerous limitations of the UKPDS study ${ }^{40}$ and lack of adequately proved efficacy. Metformin's ability to achieve weight loss rather than weight gain and lack of risk of hypoglycaemia makes it the first line treatment in international guidelines. ${ }^{5}$ On the contrary, sulfonylureas have no proved efficacy in randomised placebo controlled double blind trials. ${ }^{38}$ Although the ADVANCE study ${ }^{6}$ did not show an excess risk of mortality with glicazide MR, doubts persist about its safety. For example, UKPDS 34 calls into question the combination of metformin and sulfonylureas (all cause mortality risk ratio $1.60,95 \%$ confidence interval 1.02 to 2.52 ). ${ }^{27}$ One meta-analysis of retrospective cohort studies reported a significant $24 \%$ to $61 \%$ excess risk for all cause mortality associated with first generation sulfonylureas. Second generation sulfonylureas were associated with an excess risk of $18 \%$ to $30 \%$ for congestive heart failure. ${ }^{41}$ 
Rosiglitazone was recently withdrawn from the European market and restricted for use by the US Food and Drug Administration for safety reasons. ${ }^{42}$ The benefit:risk ratio of pioglitazone remains unclear ${ }^{43}$ given its associated risk of congestive heart failure and weight gain. ${ }^{28}$ We observed significant heterogeneity for the outcome of congestive heart failure, which was not entirely explained by using thiazolidinediones in the intensive treatment group (>90\% of patients for $\mathrm{ACCORD}^{7}$ and $100 \%$ for PROactive ${ }^{28}$ versus $<20 \%$ for ADVANCE ${ }^{6}$ ). In our analysis, the increased risk of congestive heart failure remained after the exclusion of trials using glitazone. The use of sulfonylureas ${ }^{41}$ or insulin in patients with heart failure $e^{44}$ might also explain the observed risk.

The effectiveness of long acting insulin therapy in type 2 diabetes has not been confirmed yet. Given the risk of severe hypoglycaemia ${ }^{34}$ and a possible increase in mortality, ${ }^{45}$ especially for patients with diabetes and heart failure, ${ }^{44}$ the benefit:risk ratio also seems to be uncertain in the prevention of microvascular and macrovascular complications.

New therapeutic drug classes for glucose lowering treatment should be evaluated by randomised clinical trials against placebo (on top of another treatment) using clinical outcomes. A more global approach to decrease the risk of cardiovascular disease, such as blood pressure lowering drugs and statins, should also be systematically considered when treating people with type 2 diabetes.

\section{Conclusion}

The overall results of this meta-analysis do not show a benefit of intensive glucose lowering treatment on all cause mortality or cardiovascular death. A $19 \%$ increase in all cause mortality and a $43 \%$ increase in cardiovascular mortality cannot be excluded. The small benefit on non-fatal myocardial infarctions and microalbuminuria may be offset by a significant increase in the risk of severe hypoglycaemia. The analysis, restricted to high quality studies, showed no benefit but a significantly increased risk of congestive heart failure in patients receiving intensive glucose lowering treatment. In light of these findings, more high quality randomised trials assessing morbidity and mortality outcomes are warranted to establish the best approach for glucose lowering in people with type 2 diabetes.

We thank Philippe Canet and Renée Cardoso from the French Health Authority for their contribution to bibliographical research and Kent Neal (supported by the French Cochrane Center) for reading the manuscript. Contributors: RB, TBA, CC, ES, and FG conceived the study. RB, SL, and $B C$ extracted the data. $R B, S L$, and $C C$ reviewed the selected papers. RB and TBA did the statistical analyses. RB, TBA, FG, CC, and MSE drafted the manuscript. WJM and BK assisted in the interpretation of the results. All authors read and approved the final manuscript. RB, TBA, and CC are guarantors.

\section{Funding: No specific funding.}

Competing interests: All authors have completed the ICMJE uniform disclosure form at www.icmje.org/coi_disclosure.pdf (available on request from the corresponding author) and declare: no support from any organisation for the submitted work; no financial relationships with any organisations that might have an interest in the submitted work in the previous three years; no other relationships or activities that could appear to have influenced the submitted work.

Ethical approval: Not required.

Data sharing: No additional data available.

1 Wild S, Roglic G, Green A, Sicree R, King H. Global prevalence of diabetes: estimates for the year 2000 and projections for 2030. Diabetes Care 2004;27:1047-53.
2 Coutinho M, Wang Y, Gerstein HC, Yusuf S. The relationship between glucose and incident cardiovascular events. Diabetes Care 1999:22:233-40.

3 Emerging Risk Factors Collaboration. Diabetes mellitus, fasting blood glucose concentration, and risk of vascular disease: a collaborative meta-analysis of 102 prospective studies. Lancet 2010;375:2215-22.

4 Stratton IM, Adler A, Neil AW, Matthews DR. Association of glycaemia with macrovascula and microvascular complications of type 2 diabetes (UKPDS 35): prospective observational study. BMJ 2000;321:405-12

5 Nathan DM, Buse JB, Davidson MB, Ferrannini E, Holman RR, Sherwin R, et al. Medical management of hyperglycemia in type 2 diabetes: a consensus algorithm for the initiation and adjustment of therapy. Diabetes Care 2009;32:193-203.

6 ADVANCE Collaborative Group. Intensive blood glucose control and vascular outcomes in patients with type 2 diabetes. N Engl J Med 2008;358:2560-72.

7 ACCORD Study Group. Effects of intensive glucose lowering in type 2 diabetes. $N$ Engl J Med 2008:358:2545-59.

8 Duckworth W, Abraira C, Moritz T, Reda D, Emanuele N, Reaven PD, et al: for the VADT Investigators. Glucose control and vascular complications in veterans with type 2 diabetes. N Engl J Med 2009;360:129-39.

9 Intensive blood-glucose control with sulphonylureas or insulin compared with conventional treatment and risk of complications in patients with type 2 diabetes, UKPDS 33. Lancet 1998;352:837-53.

10 Ray KK, Seshasai SR, Wijesuriya S, Sivakumaran R, Nethercott S, Preiss D, et al. Effect of intensive control of glucose on cardiovascular outcomes and death in patients with diabetes mellitus: a meta-analysis of randomised controlled trials. Lancet 2009;373:1765-72.

11 Turnbull FM, Abraira C, Anderson RJ, Byington RP, Chalmers JP, Duckworth WC, et al . Intensive glucose control and macrovascular outcomes in type 2 diabetes. Diabetologia 2009;52:2288-98.

12 Kelly TN, Bazzano LA, Fonseca VA, Thethi TK, Reynolds K, He J. Systematic review: glucose control and cardiovascular disease in type 2 diabetes. Ann Intern Med 2009;151:394-403.

13 Jadad AR, Moore RA, Carroll D, Jenkinson C, Reynolds DJ, Gavaghan DJ, et al. Assessing the quality of reports on randomized clinical trials: is blinding necessary? Control Clin Trials 1996;17:1-12.

14 Diabetes Control and Complications Trial Research Group. The effect of intensive treatment of diabetes on the development and progression of long-term complications in insulin-dependent diabetes mellitus. N Engl J Med 1993;329:977-86.

15 Malmberg K, Rydén L, Hamsten A, Herlitz J, Waldenström A, Wedel H. Effects of insulin treatment on cause-specific one-year mortality and morbidity in diabetic patients with acute myocardial infarction. DIGAMI Study Group. Diabetes insulin-glucose in acute myocardial infarction. Eur Heart J 1996;17:1337-44.

16 Kahn SE, Haffner SM, Heise MA, Herman WH, Holman RR, Jones NP, et al. Glycemic durability of rosiglitazone, metformin, or glyburide monotherapy. N Engl J Med 2006;355:2427-43.

17 Home PD, Pocock SJ, Beck-Nielsen H, Curtis PS, Gomis R, Hanefeld M, et al, RECORD Study Team. Rosiglitazone evaluated for cardiovascular outcomes in oral agent combination therapy for type 2 diabetes (RECORD): a multicentre, randomised, open-label trial. Lancet 2009;373:2125-35.

18 DREAM Trial Investigators. Effect of rosiglitazone on the frequency of diabetes in patients with impaired glucose tolerance or impaired fasting glucose: a randomised controlled trial. Lancet 2006;368:1096-105.

19 Navigator Study Group. Effect of nateglinide on the incidence of diabetes and cardiovascular events. N Engl J Med 2010;362:1463-76.

20 Gaede $\mathrm{P}$, Lund-Andersen $\mathrm{H}$, Parving $\mathrm{HH}$, Pedersen $\mathrm{O}$. Effect of a multifactorial intervention on mortality in type 2 diabetes. N Engl J Med 2008;358:580-91.

21 Holman RR, Cull CA, Turner RC. A randomized double-blind trial of acarbose in type 2 diabetes shows improved glycemic control over 3 years (UK Prospective Diabetes Study 44). Diabetes Care 1999;22:960-4.

22 University Group Diabetes Program. A study of the effects of hypoglycemic agents on vascular complications in patients with adult-onset diabetes: V. Evaluation of phenformin therapy. Diabetes 1975;24:65-184.

23 University Group Diabetes Program. A study of the effects of hypoglycemic agents on vascular complications in patients with adult-onset diabetes: V. Supplementary report on nonfatal events in patients treated with tolbutamide. Diabetes 1976;25:1129-53.

24 University Group Diabetes Program. Effects of hypoglycemic agents on vascular complications in patients with adult-onset diabetes: VIII. Evaluation of insulin therapy: final report. Diabetes 1982;31:1-81

25 Ohkubo Y, Kishikawa H, Araki E, Miyata T, Isami S, Motoyoshi S, et al. Intensive insulin therapy prevents the progression of diabetic microvascular complications in Japanese patients with non-insulin dependent diabetes mellitus: a randomized prospective 6 year study. Diab Res Clin Pract 1995;28:103-17.

26 Abraira C, Colwell J, Nuttall F, Sawin CT, Henderson W, Comstock JP, et al. Cardiovascular events and correlates in Veterans Affairs Diabetes Feasibility trial. Arch Intern Med 1997:157:181-8.

27 UK Prospective Diabetes Study (UKPDS) Group. Effect of Intensive blood-glucose control with metformin on complications in overweight patients with type 2 diabetes (UKPDS 34 ). Lancet 1998;352:854-65.

28 Dormandy JA, Charbonnel B, Eckland DJ, Erdmann E, Massi-Benedetti M, Moules IK, et al; PROactive Investigators. Secondary prevention of macrovascular events in patients with type 2 diabetes in the PROactive Study (PROspective pioglitAzone Clinical Trial In macroVascular Events): a randomised controlled trial. Lancet 2005;366:1279-89.

29 Dargie HJ, Hildebrandt PR, Riegger GA, McMurray JJ, McMorn SO, Roberts JN, et al. A randomized, placebo-controlled trial assessing the effects of rosiglitazone on echocardiographic function and cardiac status in type 2 diabetic patients with New York Heart Association Functional Class I or II Heart Failure. J Am Coll Cardiol 2007;49:1696-704.

30 Kooy A, De Jager J, Lehert P, Bets D, Wulffelé MG, Doncker AJ, et al. Long-term effects of metformin on metabolism and microvascular and macrovascular disease in patients with type 2 diabetes mellitus. Arch Intern Med 2009;169:616-25.

31 Azad N, Emanuele NV, Abraira C, Henderson WG, Colwell J, Levin SR, et al. The effects of intensive glycemic control on neuropathy in the VA cooperative study on type II diabetes mellitus (VA CSDM). J Diabetes Complications 1999;13:307-13.

32 ACCORD Study Group, ACCORD Eye Study Group. Effects of medical therapies on retinopathy progression in type 2 diabetes. N Engl J Med 2010;363:233-44. 


\section{What is already known on this topic}

Glucose lowering treatments are widely used to treat type 2 diabetes and to prevent long term cardiovascular complications as well as impairment of renal and visual functions

The benefit of such treatment on clinical end points has not been shown unambiguously

\section{What this study adds}

Overall results of this meta-analysis show that there are no benefits of intensive glucose lowering treatment on all cause mortality and deaths from cardiovascular causes in adults with type 2 diabetes

Intensive glucose lowering treatment of type 2 diabetes should be considered with caution and therapeutic escalation should be limited

33 Ismail-Beigi F, Craven T, Banerji MA, Basile J, Calles J, Cohen RM, et al. Effect of intensive treatment of hyperglycaemia on microvascular outcomes in type 2 diabetes: an analysis of the ACCORD randomised trial. Lancet 2010;376:419-30.

34 Zoungas S, Patel A, Chalmers J, de Galan BE, Li Q, Billot L, et al; ADVANCE Collaborative Group. Severe hypoglycemia and risks of vascular events and death. N Engl J Med 363:1410-8.

35 Currie CJ, Peters JR, Tynan A, Evans M, Heine RJ, Bracco OL, et al. Survival as a function of $\mathrm{HbA} 1 \mathrm{C}$ in people with type 2 diabetes: a retrospective cohort study. Lancet 2010;375:481-9

36 Shaughnessy AF, Slawson DC. What happened to the valid POEMs? A survey of review articles on the treatment of type 2 diabetes. BMJ 2003;327:266-73.

37 Gandhi GY, Murad MH, Fujiyoshi A, Mullan RJ, Flynn DN, Elamin MB, et al. Patient-important outcomes in registered diabetes trials. JAMA 2008;299:2543-9.

38 Selvin E, Bolen S, Yeh HC, Wiley C, Wilson LM, Marionopoulos SS, et al. Cardiovascular outcomes in trials of oral diabetes medications: a systematic review. Arch Intern Med 2008; $168: 2070-80$.

39 Roussel R, Travert F, Pasquet B, Wilson PWF, Smith SC, Goto S, et al: for the Reduction of Atherothrombosis for Continued Health (REACH) Registry Investigators. Metformin use and mortality among patients with diabetes and atherothrombosis. Arch Intern Med 2010;170:1892-9.
40 McCormack J, Greenhalgh T. Seeing what you want to see in randomised controlled trials: versions and perversions of UKPDS data. BMJ 2000;320:1720-3.

41 Tzoulaki I, Molokhia M, Curcin V, Little MP, Millett CJ, Ng A, et al. Risk of cardiovascular disease and all cause mortality among patients with type 2 diabetes prescribed oral antidiabetes drugs: retrospective cohort study using UK general practice research database. BMJ 2009;339:b4731.

42 Nissen SE, Wolski K. Effect of rosiglitazone on the risk of myocardial infarction and death from cardiovascular causes. N Engl J Med 2007;356:2457-71.

43 Richter B, Bandeira-Echtler E, Bergerhoff K, Clar C, Ebrahim SH. Pioglitazone for type 2 diabetes mellitus. Cochrane Database Syst Rev 2006;4:CD006060.

44 Eurich DT, McAlister FA, Blackburn DF, Majumdar SR, Tsuyuki RT, Varney J, et al. Benefits and harms of antidiabetic agents in patients with diabetes and heart failure: systematic review. BMJ 2007;335:497.

45 Gamble JM, Simpson SH, Eurich DT, Majumdar SR, Johnson JA. Insulin use and increased risk of mortality in type 2 diabetes: a cohort study. Diabetes Obes Metab 2010;12:47-53.

Accepted: 27 May 2011

Cite this as: BMJ 2011;343:d4169 


\section{Table}

Table 1 | Characteristics of studies included in meta-analysis

\begin{tabular}{|c|c|c|c|c|c|c|c|c|c|c|c|c|}
\hline Characteristic & $\begin{array}{l}\text { UGDP } \\
1975,^{22} \\
1976^{23}\end{array}$ & $\begin{array}{l}\text { UGDP } \\
1982^{24}\end{array}$ & $\begin{array}{c}\text { Kumamoto } \\
1995^{25}\end{array}$ & $\begin{array}{l}\text { Veteran } \\
\text { Affairs }^{26}\end{array}$ & $\underset{927}{\text { UKPDS }} 1998$ & $\begin{array}{c}\text { PROactive } \\
2005^{28}\end{array}$ & $\begin{array}{c}\text { Dargie et al } \\
2007^{29}\end{array}$ & $\begin{array}{l}\text { ACCORD } \\
2008^{7}\end{array}$ & $\begin{array}{c}\text { ADVANCE } \\
2008^{6}\end{array}$ & $\begin{array}{l}\text { VADT } \\
2009^{8}\end{array}$ & $\begin{array}{l}\text { HOME } \\
2009^{30}\end{array}$ & Total \\
\hline Jadad score & 4 & 3 & 2 & 2 & 3 & 5 & 5 & 3 & 3 & 3 & 4 & \\
\hline $\begin{array}{l}\text { No of } \\
\text { participants }\end{array}$ & 613 & 414 & 110 & 153 & 4209 & 5238 & 224 & 10251 & 11140 & 1791 & 390 & 34533 \\
\hline $\begin{array}{l}\text { No receiving } \\
\text { intensive } \\
\text { therapy }\end{array}$ & 408 & 204 & 55 & 75 & 3071 & 2605 & 110 & 5128 & 5571 & 892 & 196 & 18315 \\
\hline $\begin{array}{l}\text { No receiving } \\
\text { standard } \\
\text { therapy }\end{array}$ & 205 & 210 & 55 & 78 & 1138 & 2633 & 114 & 5123 & 5569 & 899 & 194 & 16218 \\
\hline Men (\%) & 29 & 29 & 50 & 100 & 47 & 66 & 80 & 62 & 58 & 97 & 50 & $60^{*}$ \\
\hline Age (years) & 52 & 52 & 49 & 60 & 53 & 62 & 64 & 62 & 66 & 60 & 61 & $61.8^{*}$ \\
\hline $\begin{array}{l}\text { Body mass } \\
\text { index }\end{array}$ & NA & NA & 20 & 31 & 28 & 31 & 29 & 32 & 31 & 31 & 30 & $31^{*}$ \\
\hline $\begin{array}{l}\text { Duration of } \\
\text { known diabetes } \\
\text { (years) }\end{array}$ & $<1$ & $<1$ & 6.5 & 7.8 & $<1$ & 8 & 4 & 10 & 8 & 11.5 & 12 & $7.8^{*}$ \\
\hline $\begin{array}{l}\text { Follow-up } \\
\text { (years) }\end{array}$ & 10 & 10 & 6 & 2.3 & 10 & 2.9 & 1 & 3.5 & 5 & 5.6 & 4.3 & $5^{\star}$ \\
\hline $\begin{array}{l}\text { Patients with } \\
\text { previous } \\
\text { cardiovascular } \\
\text { events (\%) }\end{array}$ & 9.5 & 9.5 & 0 & 27 & 0 & 100 & 35 & 35 & 32 & 40 & 1 & $39^{*}$ \\
\hline Initial FPG (g/L) & 1.43 & 1.43 & - & - & 1.45 & - & - & - & - & 一 & - & - \\
\hline Initial $\mathrm{HbA}_{1 \mathrm{c}}(\%)$ & - & - & 9 & 9.5 & 7.1 & 7.9 & 7.8 & 8.3 & 7.5 & 9.4 & 7.9 & $7.9^{*}$ \\
\hline $\begin{array}{l}\text { Final } \mathrm{HbA}_{1 \mathrm{c}}(\%) \\
\text { intensive group }\end{array}$ & NA & NA & NA & 7.0 & 7.0 & $7.0 \%$ & 7.3 & 6.4 & 6.8 & 6.9 & 7.7 & $6.7^{*}$ \\
\hline $\begin{array}{l}\text { Final } \mathrm{HbA}_{1 \mathrm{c}}(\%) \\
\text { standard group }\end{array}$ & NA & NA & NA & 9.5 & 7.9 & 7.6 & 8.0 & 7.5 & 7.3 & 8.4 & 7.9 & $7.5^{\star}$ \\
\hline $\begin{array}{l}\mathrm{HbA}_{1 \mathrm{c}} \\
\text { final-initial }\end{array}$ & NA & NA & NA & 2.5 & 0.9 & 0.6 & 0.7 & 1.1 & 0.5 & 1.5 & 0.2 & $0.8^{*}$ \\
\hline \multicolumn{13}{|l|}{$\begin{array}{l}\text { Protocol } \\
\text { treatment: }\end{array}$} \\
\hline Intensive & $\begin{array}{c}\text { Tolbutamide } \\
\text { or } \\
\text { Phenformin }\end{array}$ & $\begin{array}{l}\text { Intensive } \\
\text { insulin }\end{array}$ & $\begin{array}{c}\text { Insulin FPG } \\
<1.4 \mathrm{~g} / \mathrm{L} \\
\text { and } \mathrm{HbA}_{1 \mathrm{c}} \\
<7 \%\end{array}$ & $\begin{array}{l}\mathrm{HbA}_{1 \mathrm{c}} \\
<7 \%\end{array}$ & $\begin{array}{c}\mathrm{FPG}<6 \\
\mathrm{mmol} / \mathrm{L} \text { and } \\
\text { metformin, } \\
\text { sulfonylureas, } \\
\text { or insulin }\end{array}$ & $\begin{array}{c}\text { Pioglitazone } \\
\text { and current } \\
\text { therapy }\end{array}$ & $\begin{array}{c}\text { Rosiglitazone } \\
\text { and current } \\
\text { therapy }\end{array}$ & $\begin{array}{c}\mathrm{HbA}_{1 \mathrm{c}}<6 \% \\
\text { and } \\
\text { available } \\
\text { treatments }\end{array}$ & $\begin{array}{c}\mathrm{HbA}_{1 \mathrm{c}}<6.5 \% \\
\text { glicazide } \\
\text { alone or in } \\
\text { association }\end{array}$ & $\begin{array}{l}\mathrm{HbA}_{1 \mathrm{c}} \\
<6 \%\end{array}$ & $\begin{array}{l}\text { Insulin } \\
\text { and } \\
\text { metformin }\end{array}$ & - \\
\hline Standard & Placebo & Insulin & Insulin & $\begin{array}{c}1 \text { insulin } \\
\text { injection } \\
\text { every } \\
\text { morning }\end{array}$ & $\begin{array}{c}\mathrm{FPG}<15 \\
\mathrm{mmol} / \mathrm{L} \text { and } \\
\text { diet }\end{array}$ & $\begin{array}{c}\text { Placebo and } \\
\text { current } \\
\text { therapy }\end{array}$ & $\begin{array}{c}\text { Placebo and } \\
\text { current } \\
\text { therapy }\end{array}$ & $\begin{array}{c}\mathrm{HbA}_{1 \mathrm{c}} \\
7-7.9 \% \\
\text { and } \\
\text { available } \\
\text { treatments }\end{array}$ & $\begin{array}{l}\text { Standard } \\
\text { glucose } \\
\text { control (with } \\
\text { target } \\
\text { glycated } \\
\text { haemoglobin } \\
\text { levels) }\end{array}$ & $\begin{array}{l}\mathrm{HbA}_{1 \mathrm{c}} \\
<9 \%\end{array}$ & $\begin{array}{l}\text { Insulin } \\
\text { and } \\
\text { placebo }\end{array}$ & - \\
\hline
\end{tabular}

$\mathrm{FPG}=$ fasting plasma glucose; $\mathrm{NA}=$ not available.

*Mean values. 


\section{Figures}

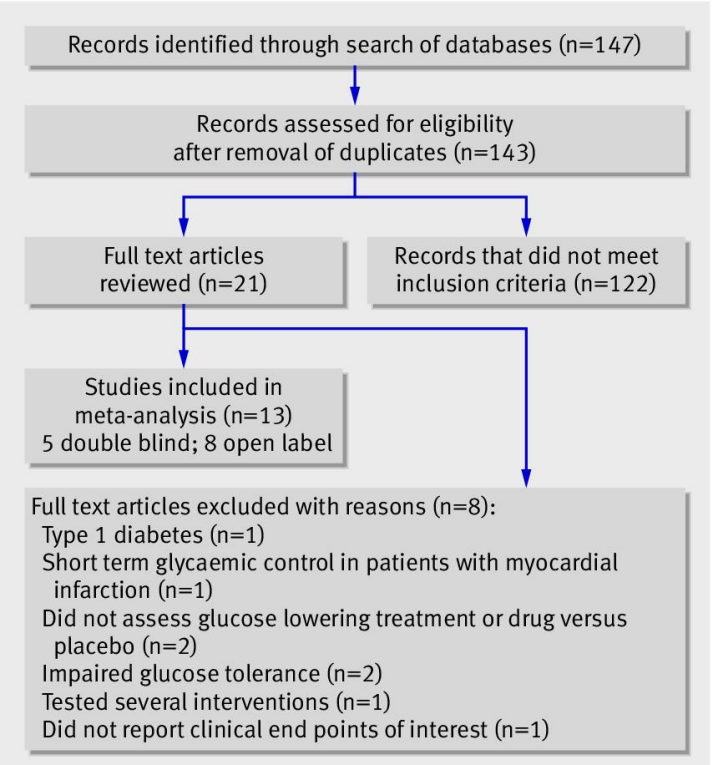

Fig 1 Flow of studies through review

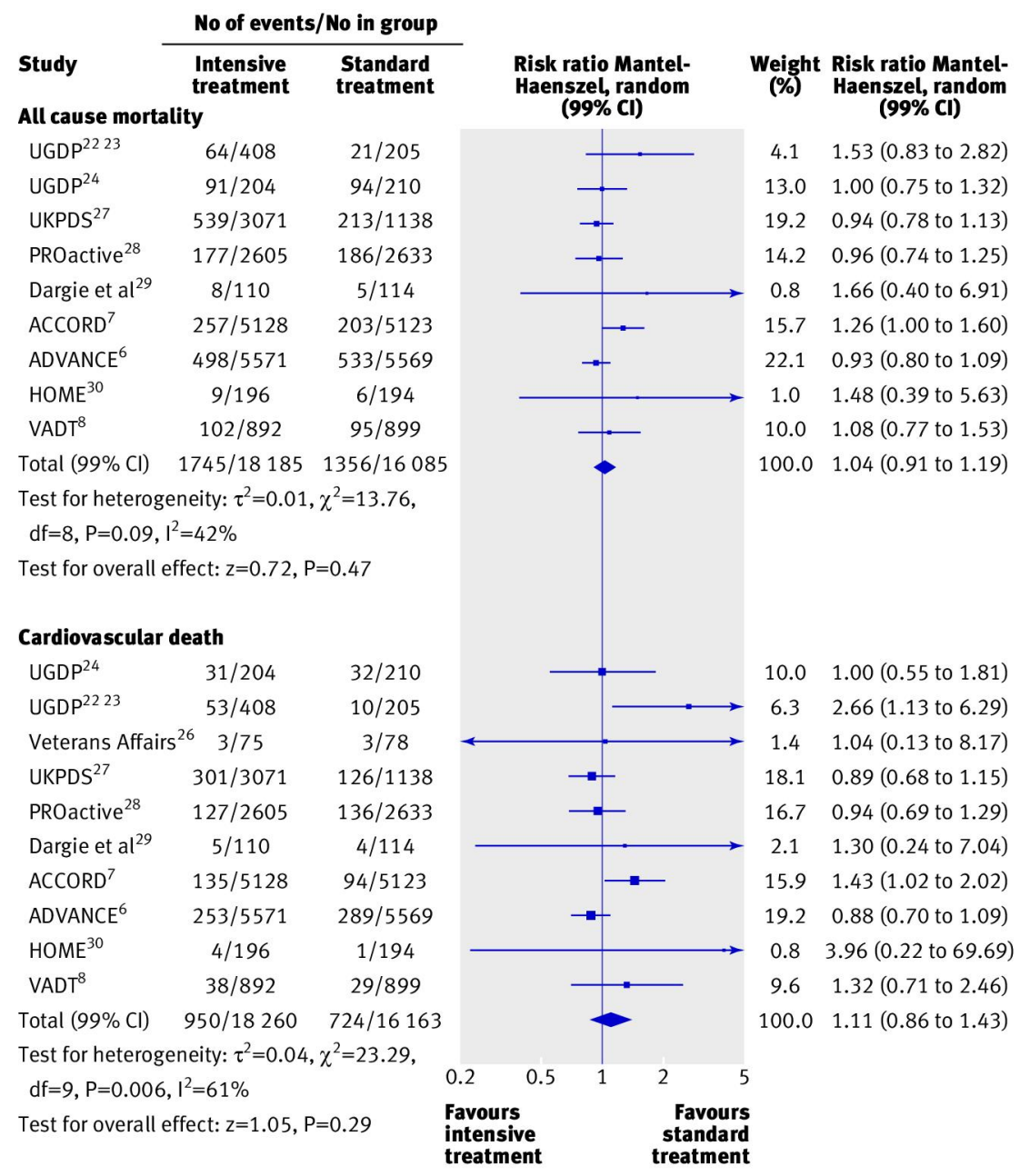

Fig 2 Forest plot for all cause mortality and death from cardiovascular causes 


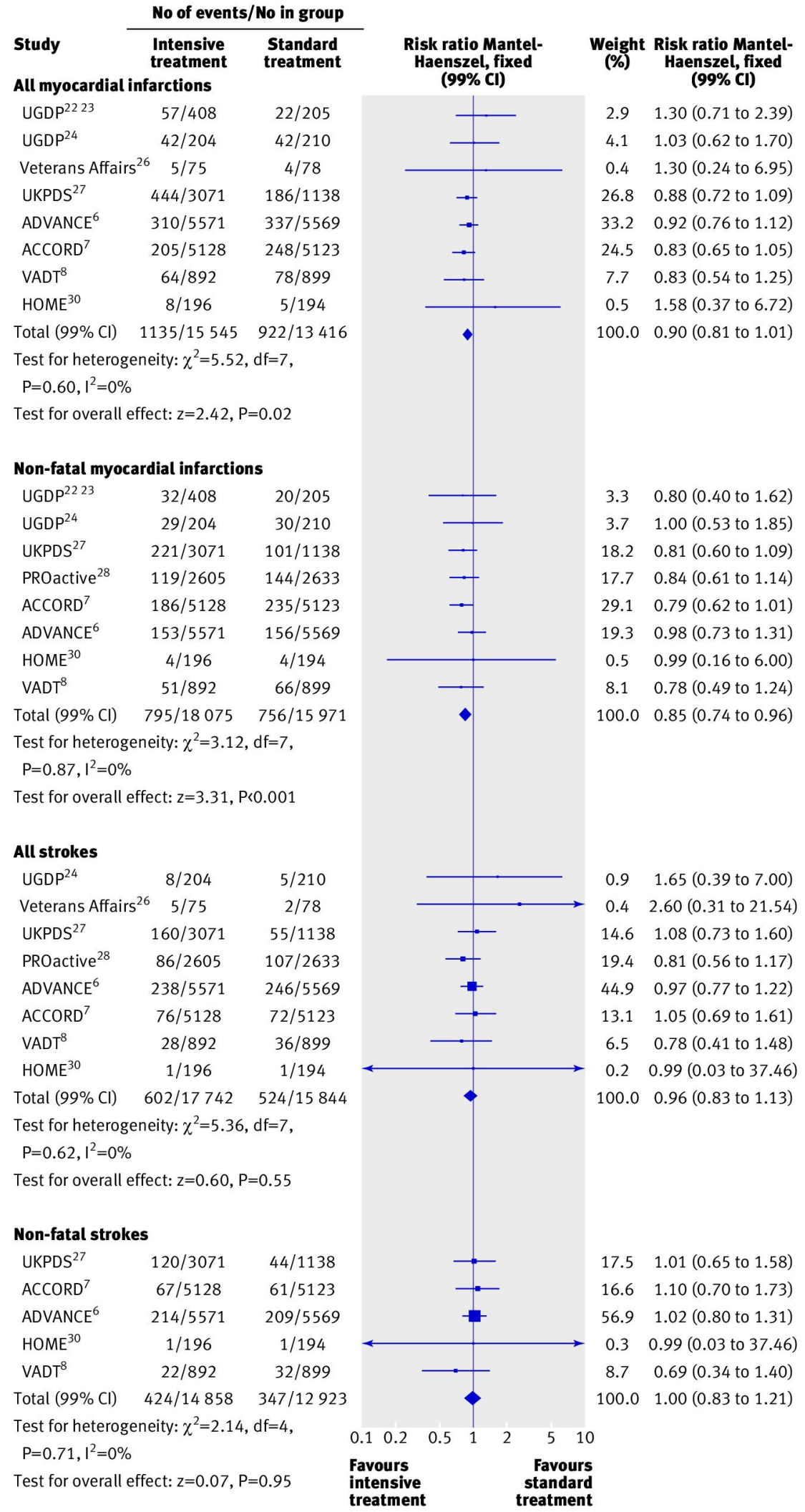

Fig 3 Forest plot for macrovascular events: myocardial infarction (fatal and non-fatal) and stroke (fatal and non-fatal). Data on myocardial infarctions not available for PROactive ${ }^{28}$ 


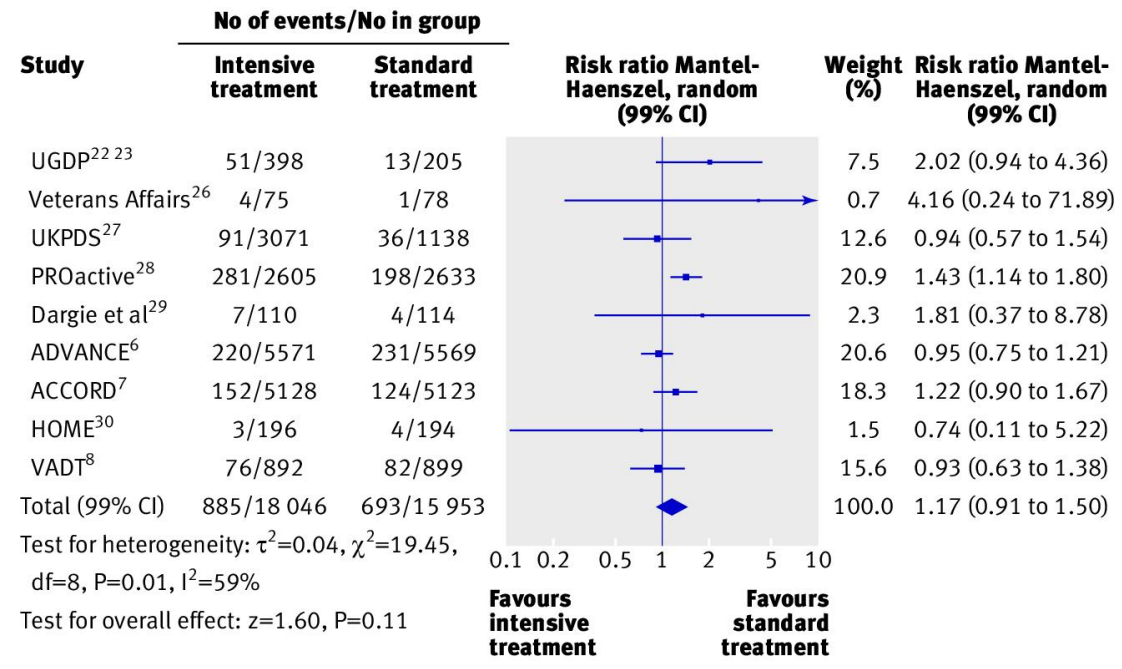

Fig 4 Forest plot for macrovascular event of congestive heart failure

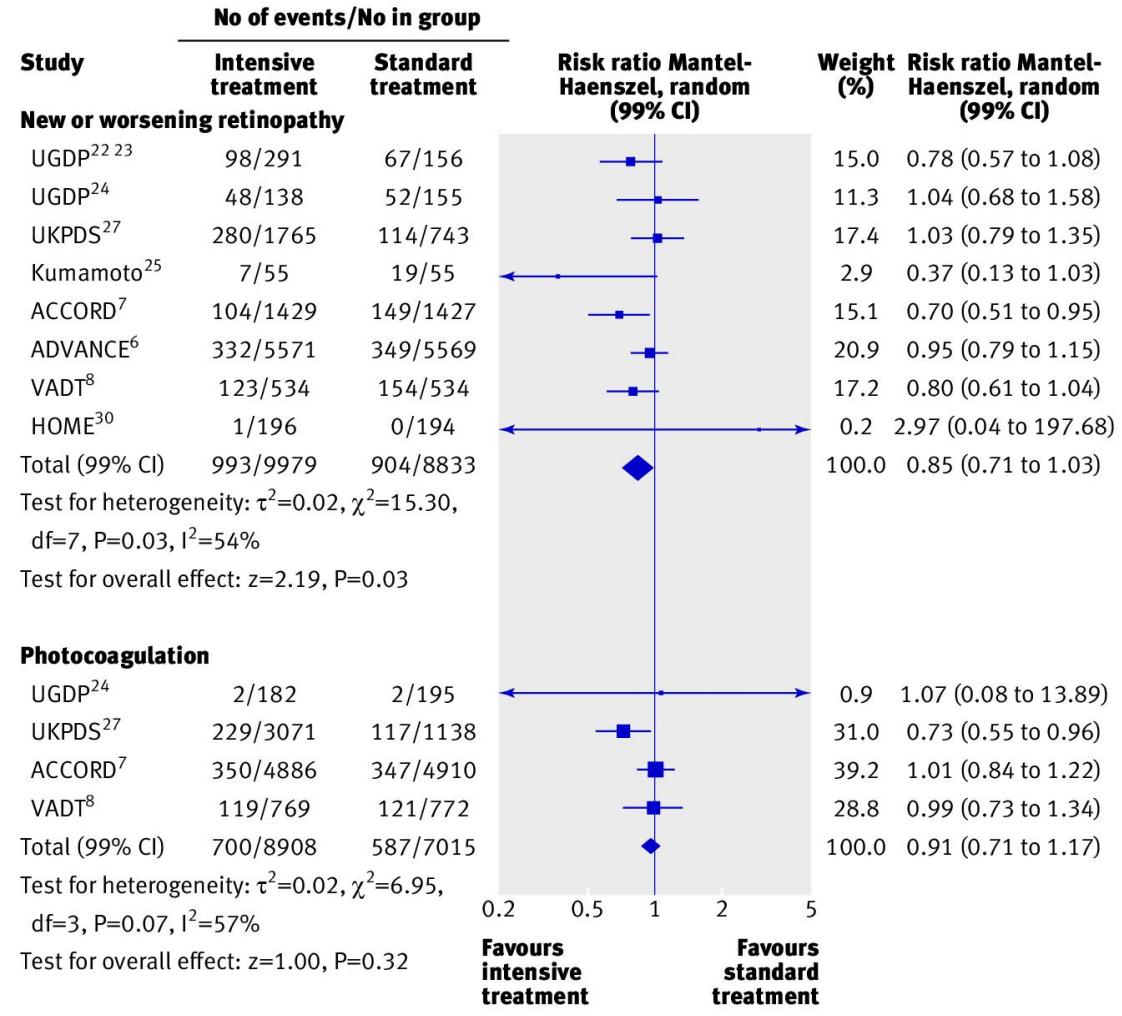

Fig 5 Forest plot for microvascular events: retinopathy and photocoagulation 
No of events/No in group

\begin{tabular}{lcc} 
Study & $\begin{array}{c}\text { Intensive } \\
\text { treatment }\end{array}$ & $\begin{array}{c}\text { Standard } \\
\text { treatment }\end{array}$ \\
\multicolumn{3}{c}{ Visual deterioration or blindness } \\
UGDP22 23 & $27 / 354$ & $12 / 179$ \\
UGDP $^{24}$ & $21 / 174$ & $22 / 180$ \\
UKPDS $^{27}$ & $90 / 3071$ & $38 / 1138$ \\
ACCORD $^{7}$ & $258 / 4651$ & $273 / 4689$ \\
ADVANCE $^{6}$ & $3033 / 5571$ & $3015 / 5569$ \\
Total $(99 \%$ Cl) & $3429 / 13821$ & $3360 / 11755$ \\
Test for heterogeneity: $\chi^{2}=1.06, d f=4$, \\
P=0.90, $I^{2}=0 \%$ \\
Test for overall effect: $z=0.01, P=0.99$
\end{tabular}

\section{New or worsening neuropathy}

Veterans Affairs $^{26} \quad 12 / 75$

$381 / 2437$

ADVANCE $^{6}$

$2353 / 5571$

$12 / 78$

$\mathrm{ACCORD}^{7}$

$1277 / 2815$

$167 / 1014$

$2311 / 5569$

$\mathrm{VADT}^{8}$

$202 / 464$

$1338 / 2791$

$19 / 196$

$218 / 498$

$18 / 194$

Total $(99 \%$ Cl) $\quad 4244 / 11558 \quad 4064 / 10144$

Test for heterogeneity: $\chi^{2}=4.33, \mathrm{df}=5$,

$\mathrm{P}=0.50, \mathrm{I}^{2}=0 \%$

Test for overall effect: $z=0.62, P=0.54$

\section{New or worsening microalbuminuria}

$\begin{array}{lcc}\text { UGDP }^{22} 23 & 15 / 187 & 15 / 191 \\ \text { UGDP }^{24} & 22 / 384 & 9 / 186 \\ \text { UKPDS }^{27} & 305 / 2538 & 152 / 1048 \\ \text { Kumamoto }^{25} & 5 / 55 & 10 / 55 \\ \text { PROactive }^{28} & 555 / 2218 & 563 / 2225 \\ \text { ACCORD }^{7} & 399 / 3204 & 494 / 3232 \\ \text { ADVANCE }^{6} & 1318 / 5571 & 1434 / 5569 \\ \text { HOME }^{30} & 15 / 196 & 14 / 194 \\ \text { VADT }^{8} & 30 / 728 & 48 / 731\end{array}$

Total $(99 \% \mathrm{Cl}) \quad 2664 / 15081 \quad 2739 / 13431$

Test for heterogeneity: $\chi^{2}=11.64, \mathrm{df}=8$,

$\mathrm{P}=0.17, \mathrm{I}^{2}=31 \%$

Test for overall effect: $z=4.18, P<0.001$

\section{Renal failure or doubling of serum} creatinine level

UGDP 2223

$U_{G D P} 24$

UKPDS $^{27}$

$\mathrm{ACCORD}^{7}$

ADVANCE $^{6}$

$48 / 374$

$19 / 187$

$18 / 3071$

$2701 / 5035$

$67 / 5571$

$78 / 882$

$25 / 181$

$16 / 191$

$9 / 1138$

$2627 / 5034$

$61 / 5569$

$78 / 884$

Total $(99 \%$ Cl) 2931/15 $120 \quad 2816 / 12997$

Test for heterogeneity: $\chi^{2}=1.27, \mathrm{df}=5$,

$\mathrm{P}=0.94, \mathrm{I}^{2}=0 \%$

Test for overall effect: $z=1.44, P=0.15$

\section{Peripheral vascular events}

$U_{G D P^{22} 23} \quad 59 / 367$

$U_{G D P^{24}} \quad 32 / 181$

Veterans Affairs $^{26} \quad 3 / 75$

UKPDS $^{27} \quad 35 / 3071$

PROactive $^{28} \quad 80 / 2605$

ADVANCE $^{6} \quad 343 / 5571$

VADT $^{8} \quad 28 / 892$

$\mathrm{HOME}^{30}$

$$
7 / 196
$$

Total $(99 \% \mathrm{Cl}) \quad 587 / 12958 \quad 553 / 10884$ Test for heterogeneity: $\chi^{2}=10.53, \mathrm{df}=7$, $\mathrm{P}=0.16, \mathrm{I}^{2}=34 \%$

Test for overall effect: $z=0.39, P=0.69$

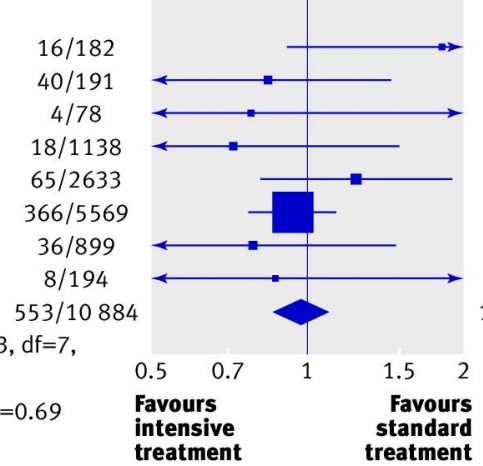

Fig 6 Forest plot for microvascular events: visual deterioration or blindness, neuropathy, microalbuminuria, renal failure or doubling of serum creatinine level, and peripheral vascular events (leg revascularisation, peripheral arterial disease, or intermittent claudication) 


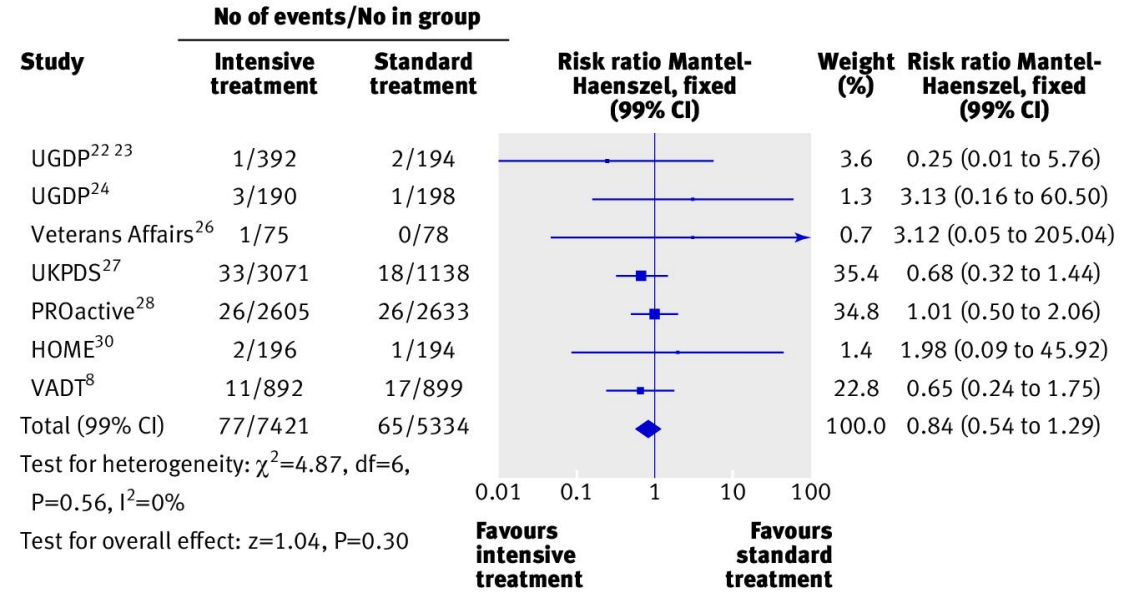

Fig 7 Forest plot for microvascular event of amputation (fatal and non-fatal)

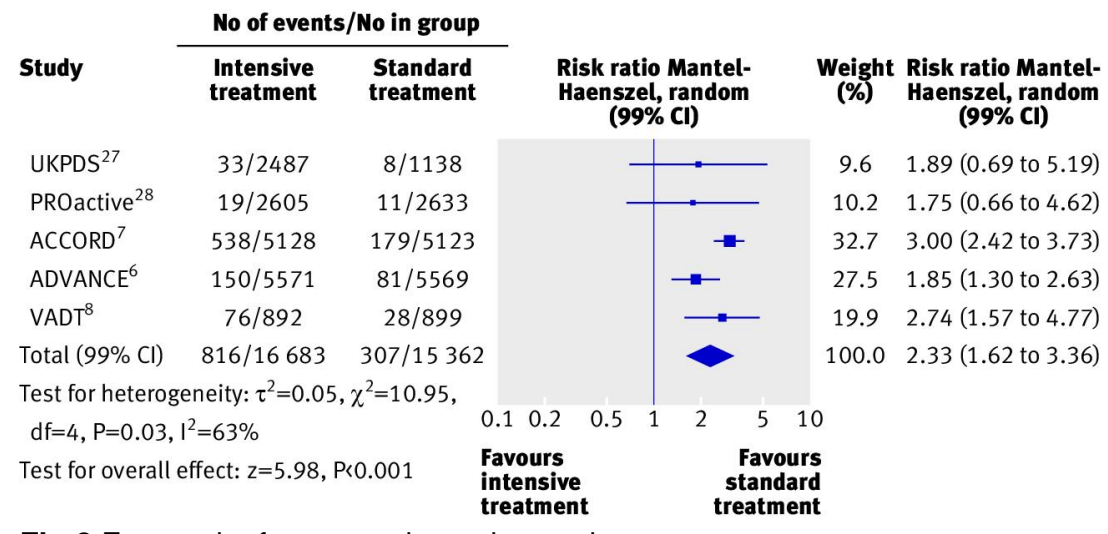

Fig 8 Forest plot for severe hypoglycaemia 